\title{
GENE EXPRESSION AND TRANSMISSION IN KERRIA LACCA (KERR)
}

\author{
N. S. CHAUHAN \\ Indian Lac Research Institute, Namkum, Ranchi, Bihar, India
}

Received 17.vi.76

\begin{abstract}
Summary
Cytological studies of the Indian lac insect Kerria lacca (Kerr) resulted in contrary reports suggesting two quite distinct chromosome systems, the orthodox and the unorthodox "Lecanoid" system. Genetic tests with the first discovered mutant, namely yellow, confirmed elimination of the paternal chromosome in $K$. lacca, but unlike the "Lecanoid" system the male was found to express the paternal allele. The results reported here with the other marker genes provide further evidence that the unorthodox genetic system of $K$. lacca differs from the "Lecanoid" system in gene expression.
\end{abstract}

\section{INTRODUGTION}

THE coccids are noteworthy for their diverse and complex genetic system; those involving heterochromatisation are of particular interest for the problem of gene and chromosome inactivation. The Indian lac insect Kerria lacca (Kerr) (Syn. Laccifer lacca (Kerr)) is an economically important species, and has, therefore, attracted attention. However, the cytological picture remains rather confused. Thus, while Tulsyan (1963) reported normal chromosome behaviour with $\mathrm{XX}$ : XO sex-determining mechanism, Dikshith $(1964 a, b)$ suggested the unorthodox "Lecanoid" system as determined in the mealy bug, Planococcus citri. Genetic tests with the yellow mutant (Chauhan, 1970) suggested a different situation for although elimination of the paternal chromosome was confirmed during the formation of the male sex-cells, unlike the "Lecanoid" system both the maternal and paternal chromosomes appeared to be somatically active. The present communication reports results obtained with the other marker genes that are now available in $K$. lacca which help clarify the situation.

\section{Materials ANd methods}

All experiments were carried out in the Institute Plantation at Namkum. The insects used in these experiments originated from the laboratory maintained homozygous wild-type and mutant stocks of $K$. lacca. The test insects were cultured on potted plants of Moghania macrophylla (Willd.) O.Ktze. covered by a fine muslin cloth cage to control contamination and prevent losses due to parasitic and predatory activity. For the tests involving colour genes, the progeny was scored at the time of sexual maturity since the lac larvae, on hatching, invariably retain the colour of their mother and the change in colour produced by their own genotype becomes apparent only after they have grown on the host plant for some time, usually in the 
second instar (Chauhan, 1967). The sexes were also scored at about this time when they were clearly distinct. Five or more progeny were scored from each class of mating.

\section{REsUlts}

The genetic stocks of $K$. lacca used in the present tests included the wildtype crimson which produces a yellow resin and the following mutants.

rellow (y). The yellow lac insect has been known for some time (Negi, 1954), but only recently established as a mutant (Chauhan, 1967). The body colour is changed from crimson to yellow and it behaves as a simple recessive.

White $(\mathrm{w})$. This mutant was first picked up in a $\mathrm{F}_{4}$ progeny from a cross of two distinct races of $K$. lacca (Chauhan and Teotia, 1973) and was later recorded occurring in low frequencies in two of the eight wild stocks of $K$. lacca maintained at this Institute (Chauhan, 1976).

The mutant is conspicuous because of the dye-free state of the insect and its resin, which behaves like a simple recessive and is non-allelic to the yellow (N. S. Chauhan, unpublished). Homozygosity for the recessive

TABLE 1

Progeny phenotypes in crosses of white $(\mathrm{w})$ and wild-type $\left(\mathrm{w}^{+}\right)$stocks of $\mathrm{K}$. lacca

\begin{tabular}{|c|c|c|c|c|c|c|c|}
\hline \multicolumn{2}{|c|}{ Genotype of } & \multirow{2}{*}{$\begin{array}{l}\text { No. of } \\
\text { progenies }\end{array}$} & \multicolumn{2}{|c|}{ Daughters } & \multicolumn{2}{|c|}{ Sons } & \multirow{2}{*}{$\begin{array}{c}\text { Expected } \\
\text { genotype } \\
\text { of sons }\end{array}$} \\
\hline Mother & Father & & Wild-type & White & Wild-type & White & \\
\hline$w^{+} / w^{+}$ & $w / w$ & 7 & 979 & 0 & 297 & 0 & $w^{+} /(w)$ \\
\hline$z w / w$ & $w^{+} / w^{+}$ & 9 & 314 & 0 & 132 & 0 & $w /\left(2 w^{+}\right)$ \\
\hline
\end{tabular}

The allele contributed by the father is shown in parcntheses.

allele at the white locus masks the manifestation of colour genes at the yellow locus, presenting a situation that is referred to as recessive epistasis in the classical sense. The expression of normal insect colour in $K$. lacca is thus dependent on the presence of at least one dominant allele at each of these two loci.

Kusmi. The so called rangeeni and kusmi strains of $K$. lacca differ most conspicuously in their ability to utilise Schleichera oleosa (Lour) Oken. as the host plant (Glover, 1937). Chauhan and Mishra (1970) have shown that the kusmi strain is genetically adapted for survival on $S$. oleosa, but the rangeeni strain is not. The kusmi phenotype is dominant to that of the rangeeni.

The progeny phenotypes in crosses of the colour forms are shown in tables 1 and 2. These results are similar to those obtained earlier with the yellow mutant (Ghauhan, 1970). The identical phenotype of the reciprocal $\mathrm{F}_{1}$ males in crosses of the white and wild-type (table 1) and expression of the wild-type phenotype by the $F_{1}$ males in crosses of the white and yellow mutants (table 2) provide further evidence that both the maternal and paternal chromosomes are somatically active in the male $K$. lacca.

The characteristic physiological difference of the rangeeni and kusmi strains of $K$. lacca in their ability to utilise $S$. oleosa as the host plant could also be used to test the somatic activity of chromosomes in the male $K$. lacca. 
TABLE 2

Progeny phenotypes in crosses of the white $(\mathrm{w})$ and yellow $(\mathrm{y})$ mutant stocks of $\mathrm{K}$. lacca

$\overbrace{\text { Mother }}^{\text {Fenotype of }} \begin{gathered}\text { Father } \\ \begin{array}{cc}w^{+} / w^{+} y / y / w y^{+} / y \\ w / w y^{+} / y^{+} & w \\ w & w^{+} / w^{+} y / y\end{array}\end{gathered}$

$\begin{array}{ccc}\begin{array}{c}\text { No. of } \\ \text { progenies }\end{array} & \overbrace{\text { Wild-type }}^{\text {Daughters }} & \begin{array}{c}\text { Mutant } \\ 6\end{array} \\ 7 & 275 & 0 \\ 7 & 270 & 0\end{array}$

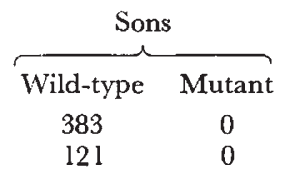

Expected genotype of sons

The allele contributed by the father is shown in parentheses.

If the paternal chromosomes are indeed inactivated as in the "Lecanoid" system, we would expect the $\mathrm{F}_{\mathbf{1}}$ progenies from rangeeni mothers and kusmi fathers, when cultured on $S$. oleosa, to contain no males at all. It will be seen from table 3 that such progenies included both sons and daughters and the average proportion of males does not differ much from that in the kusmi progenies.

TABLE 3

Average percentage males in crosses of rangeeni and kusmi stocks of $\mathrm{K}$. lacca when cultured on $\mathrm{S}$. oleosa

$\begin{array}{ccccc}\text { Mother } & \text { Father } & \overbrace{\text { Daughters }} & \text { Sons } & \% \text { males } \\ \text { kusmi } & \text { kusmi } & 1551 & 204 & 11 \cdot 6 \\ \text { rangeeni } & \text { kusmi } & 990 & 167 & 14 \cdot 4\end{array}$

Earlier tests with the yellow mutant (Chauhan, 1970) had confirmed that the male transmitted only the maternal chromosome through the sperm. The reciprocal $F_{1}$ males and females from crosses of the white and wild-type stocks of lac insects were also backcrossed to the recessive homozygous parent to test the kinds of gamete they produced. Table 4 shows that, as expected, the heterozygous females produced two kinds of gamete, but the heterozygous males produced only the maternal kind, providing further confirmation that the paternal chromosome is not transmitted through the sperm. Similar results have since been obtained in crosses of the white and yellow mutants, the $\mathrm{F}_{2}$ always behaving like a backcross to the maternal parent due to the male transmitting only the maternal chromosomes through the sperm.

It will be seen from tables 1,2 and 4 that the number of progeny scored

TABLE 4

The test-cross distribution of white $(\mathrm{w})$ and wild-type $\left(\mathrm{w}^{+}\right)$in crosses of the two colour forms of $\mathrm{K}$. lacca

$\begin{array}{llc}\text { Mother } & \text { Father } & \begin{array}{c}\text { No. of } \\ \text { progenies }\end{array} \\ w /\left(w^{+}\right) & w /(w) & 5 \\ w^{+} /(w) & w /(w) & 5 \\ w /(w) & w /(w+) & 7 \\ w /(w) & w^{+} /(w) & 8\end{array}$

\begin{tabular}{|c|c|}
\hline \multicolumn{2}{|c|}{ Daughters } \\
\hline Wild-type & White \\
\hline 369 & 341 \\
\hline 296 & 281 \\
\hline 0 & 251 \\
\hline 301 & 0 \\
\hline
\end{tabular}

\begin{tabular}{|c|c|}
\hline \multicolumn{2}{|c|}{ Sons } \\
\hline Wild-type & White \\
\hline 114 & 97 \\
\hline 101 & 89 \\
\hline 0 & 71 \\
\hline 97 & 0 \\
\hline
\end{tabular}

The allele contributed by the father is shown in parentheses. 
from the crosses with white as the maternal parent were distinctly fewer than those from the others, and this was certainly due to the reduced fecundity and survival of the white mutant.

\section{Discussion}

The results in the present tests are similar to those obtained earlier with the yellow mutant. The identical phenotype of the reciprocal $F_{1}$ males in crosses of the white and wild-type, the expression of wild-type phenotype by the $\mathrm{F}_{1}$ males from crosses of the white and yellow mutants, and the normal survival of $\mathrm{F}_{1}$ males from crosses of the rangeeni mothers and kusmi fathers on $S$. oleosa leave no doubt that both the maternal and paternal chromosomes are somatically active in the male $K$. lacca. The fact that the paternal alleles for the known loci in $K$. lacca are expressed in the male presents a situation distinctly different from that demonstrated for the "Lecanoid" system by Brown and Nur (1964), Brown (1969) and Brown and Wiegmann (1969). Although Dikshith claims a "Lecanoid" system in K. lacca, his actual observations relate only to spermatogenesis, and this is confirmed in the genetic tests. The available cytogenetic evidence thus clearly suggests that the heterochromatisation of the paternal chromosome-set is confined to the male germ line. The $K$. lacca genes are thus autosomal in expression, but sex-linked in transmission.

Of the coccid systsms involving heterochromatisation and elimination of chromosomes, the "Lecanoid" has been considered the ancestral one and derived from the orthodox XX : XO system (Brown and McKenzie, 1962; Brown, 1963). The cytological features of the $K$. lacca system closely resemble those of the "Lecanoid" (Dikshith, 1964a,b), but for the fact that the former still retains the diploid somatic status of the male. It is tempting, therefore, to consider the $K$. lacca system as the progenitor of the "Lecanoid" system.

Acknowledgment.-I am grateful to Dr T. P. S. Teotia, Director, for his encouragement.

\section{REFERENGES}

BROWN, s. w. 1963. The Comstockiella system of chromosome behaviour in the armored scale insects (Coccoidea:Diaspididae). Chromosoma, 14, 360-406.

BROWN, s. w. 1969. Developmental control of heterochromatization in coccids. Genetics, 61 (No. 1, part 2, a supplement), 191-198.

BROWN, s. W., AND MCKENZIE, H. L. 1962. Evolutionary patterns in the armored scale insects and their allies (Homoptera:Coccoidea:Diaspididae, Phoenicococcidac, and Asterolecaniidae). Hilgardia, 33, 141-170A.

BROWN, s. W., AND NUR, U. 1964. Heterochromatic chromosomes in the coccids. Science, 145, 130-136.

Brown, s. W., AND WIEgmanN, L. I. 1969. Cytogenetics of the Mealy bug Planococcus citri (Risso) (Homoptera:Coccoidea):Genetic markers, lethals and chromosome rearrangements. Chromosoma, 28, 255-279.

chauhan, N. s. 1967. A colour mutant in the Indian lac insect. Indian 7. Ent., 29, 216-217. chauhan, N. s. 1970. Genetic evidence of an unorthodox chromosomal systein in the lac insect Kerria lacca (Kerr). Genet. Res., Camb., 16, 341-344.

GHAUHAN, N. s. 1976. Low frequency occurrence of the white lac variant in natural populations of Kerria lacca (Kerr). Curr. Sci., 45, 566.

CHAUHAN, N. s., AND mishra, Y. D. 1970. Genetic evidence of nutritional differences in lac insects. Indian 7. Ent., 32, 390-392. 
Ghauhan, N. s., AND TEOTiA, T. P. s. 1973. Note on a newly discovered lac insect producing white lac. Indian 7. agric. Sci., 43, 1086-1087.

Dikshiтн, т. s. s. 1964a. Chromosome behaviour in Laccifer lacca (Kerr) LacciferidaeCoccoidea. Cytologia, 29, 337-345.

DiKshiтh, т. s. s. 1964b. Spermatogenesis in Laccifer lacca (Kerr) Lacciferidae-Coccoidea: A correction. Indian $\mathcal{F}$. Ent., 26, 367-369.

GLOVER, P. M. 1937. Lac cultivation in India. Indian Lac Research Institute, Sri Gouranga Press, Calcutta.

NEGI, P. s. 1954. Dimorphism in lac insects. Indian Forester, 80, 423-426.

TULSYAN, G. P. 1963. Studies on chromosome number and spermatogenesis in the lac insect Laccifer lacca (Kerr). Curr. Sci., 32, 374-375. 